\title{
Reações iniciais do paciente infanto-juvenil ante a indicação de cirurgia de estrabismo
}
First
reactions
of the
patient
when facing
strabismus
surgery
indication

$\begin{array}{lccc}\text { Maria } & \text { Cristina } & \text { Oliveira Regina } \\ \text { Keila } & \text { Monteiro de Carvalfio } & \\ \text { Rodolfo } & \text { José Rodrigues da } & \text { Silva }\end{array}$

Trabalho realizado no Centro de Estudos e Pesquisa em Reabilitação-CEPRE/Universidade Estadual de Campinas - UNICAMP.

${ }^{1}$ Psicóloga/docente em educação especial e reabilitação.

${ }^{2}$ Oftalmologista, Mestre /Doutora.

${ }^{3}$ Médico-residente em oftalmologia (R3).

Endereço para correspondência: R. Heitor Leme de Paula, 44 - Campinas (SP) CEP 13024-550. E-mail: moregina@uol.com.br

\section{RESUMO}

Objetivo: O presente trabalho pretendeu identificar as principais reações de crianças em face de cirurgia de estrabismo resultantes de sua imediata e recente indicação em consulta médica. Métodos: Pesquisa - Ação. Resultados: Ansiedade e medo foram os mais importantes sentimentos encontrados. Parecem ser sustentados por conceitos parciais formados sobre cirurgia a partir do estágio de desenvolvimento cognitivo e emocional das crianças. Motivação própria ou pessoal para a cirurgia somente mostrou-se reconhecível entre sujeitos mais velhos: a partir de 9 anos de idade. Crianças com menos idade têm seu desejo/motivação para cirurgia, mesclado, ou até mesmo confundido, com os objetivos dos adultos que as rodeiam, especialmente os pais. Conclusões: O significado especial destes dados nos remete à função simbólica. Ela deve ser considerada para o preparo psicológico das crianças para cirurgia, em ambas as direções: no âmbito cognitivo e emocional/afetivo.

Descritores: Estrabismo/cirurgia; Estrabismo/psicologia; Ansiedade; Medo; Cognição; Relações pais-filho; Transtornos do comportamento infantil/psicologia; Participação do paciente

\section{INTRODUÇ̃̃O}

Vários estudos tem demonstrado interesse em verificar as conseqüências psicológicas do evento cirúrgico para pacientes e familiares, especialmente pais ${ }^{(1)}$, em se tratando de cirurgia de criança. Há registro de alterações tanto de curto $^{(2)}$ como de longo prazo, algumas vezes permeadas por experiências anteriores de contato médico, hospitalar ou cirúrgico ${ }^{(3)}$.

Alguns estudos identificaram fatores indicativos de possíveis alterações de comportamento da criança ante a perspectiva de cirurgia: idade da criança, ansiedade dos pais, possibilidade ou vivências anteriores de dor ${ }^{(4)}$. Outros estudos apontam além da idade da criança, o número de irmãos, a imediata ansiedade pré-operatória da criança e da mãe e a qualidade dos encontros médicos como preditores de ansiedade pré-operatória ${ }^{(5)}$.

Não se pode portanto deixar de considerar na análise dos fatores que podem contribuir para a reação da criança ante a cirurgia, o relacionamento médico-paciente estabelecido, o período de desenvolvimento cognitivo da criança, a postura dos pais ante o evento e, neste caso específico, o objetivo pretendido com a intervenção.

\section{MÉTODOS}

Este trabalho foi realizado no ambulatório de oftalmologia da Unicamp. O método utilizado neste trabalho foi a pesquisa-ação, através de entrevista 
semi-estruturada aplicada em crianças de 4 a 14 anos de idade, que receberam um padrão mínimo de informações uniformes da equipe médica sobre a cirurgia (necessidade de cirurgia, tipo de anestesia, data da cirurgia, possibilidade de prévia internação).Todos os pacientes da amostra foram entrevistados após consulta de indicação de cirurgia, antes ou depois de tomadas as medidas oculares necessárias. Os pais, que manifestaram sua anuência, acompanharam os sujeitos durante a entrevista permanecendo no recinto.

\section{RESULTADOS E DISCUSSÃO}

Note-se que a faixa etária prevalente nesta amostra foi o intervalo entre 4 e 10 anos de idade (de 4 a 7 anos: 10 sujeitos e, de 8 a 10 anos: 11 sujeitos). Considerando-se o 3 subgrupos observou-se uma relativa predominância de sujeitos do sexo feminino, o que provavelmente segue uma tendência de distribuição na população em geral.

Relativamente à escolaridade note-se que a maioria da amostra freqüentava escola comum à época da entrevista, predominando o período entre o jardim de infância e a $3^{\text {a }}$ série do $1^{\circ}$ Grau.

Pode-se notar que os sentimentos dos pacientes imediatamente após consulta médica para indicação de cirurgia, revela-

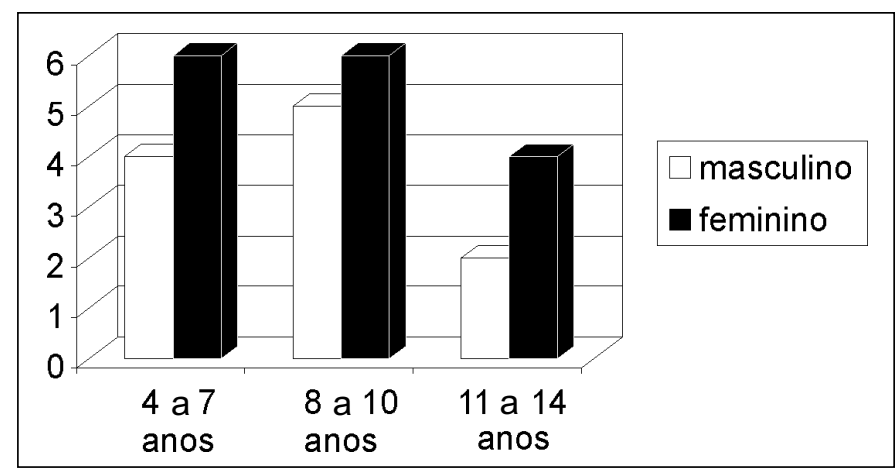

Gráfico1 - Faixa etária dos sujeitos da amostra

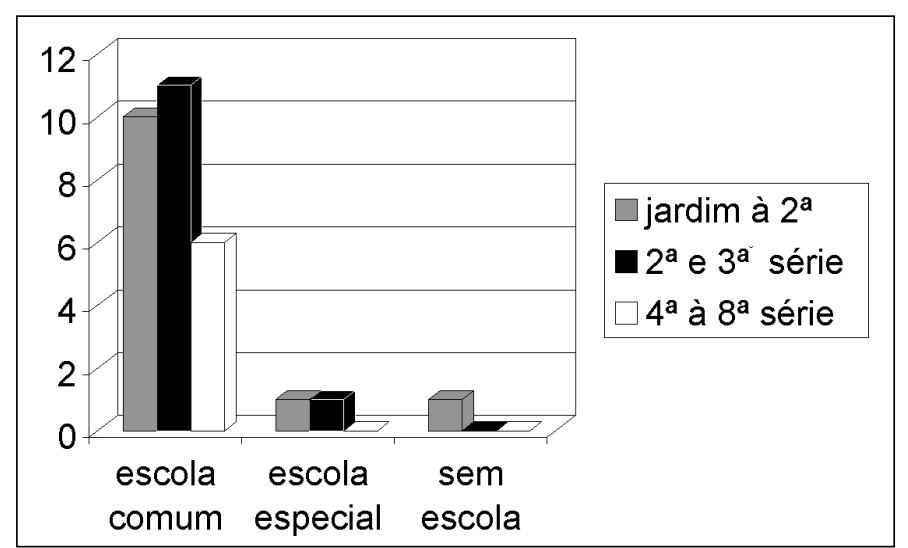

Gráfico 2 - Escolaridade dos sujeitos da amostra ram-se mais satisfatórios que os sentimentos antecedentes a ela. Certo paciente comentou diretamente sua satisfação por ter sido indicada a intervenção, demonstrando quão aguardado era seu objetivo. Entre alguns dos sujeitos que apresentaram ansiedade, dor de cabeça ou cansaço antes da consulta, aparentemente não conservaram este estado posteriormente. Entre outros sujeitos que se mostravam cansados, ou com sono aparentemente mantêve-se o estado apresentado antes da consulta, o que pode ser interpretado como, para além da circunstância de espera, algo reativo ao procedimento discutido.

A postura dos pais em geral não foi a de omitir informações à criança, se as possuíam, entretanto entre pais de crianças com mais tenra idade observou-se esta tendência.

À parte o grau de participação envolvido, o fato é que maioria dos sujeitos desta amostra sentiu-se participante da decisão de realizar a consulta, quer pelo fato de concordarem com ela, ou de confiarem na capacidade de decisão de seus pais, quer, simplesmente, por aceitarem-na, uma vez que a decisão foi tomada por eles, sentindo-se aparentemente respeitados nela. Participação ativa propriamente dita ocorreu minoritariamente e foi indicada por crianças mais velhas. Entre os que não se sentiram participantes da decisão, a maior parte a atribuiu aos médicos ou aos pais, sem maiores comentários. Poucos de fato nada sabiam ao chegarem à consulta.

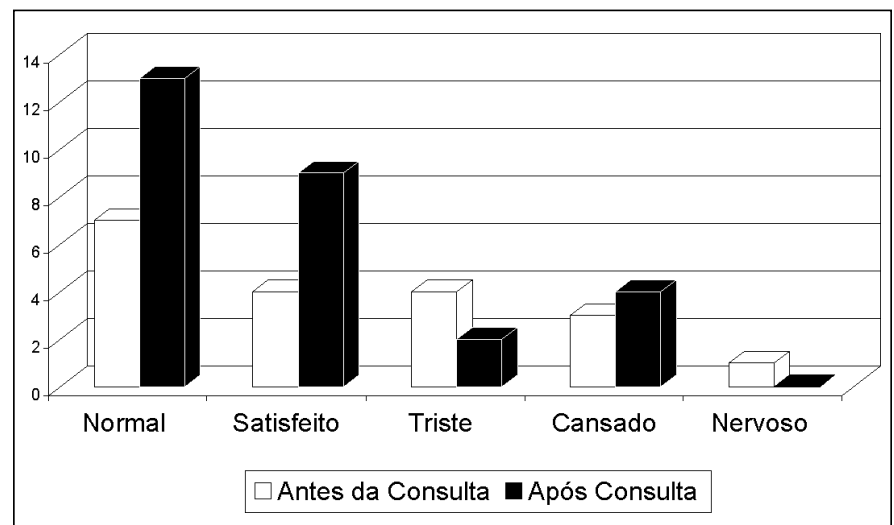

Gráfico 3 - Sentimento dos pacientes antes e depois da consulta médica

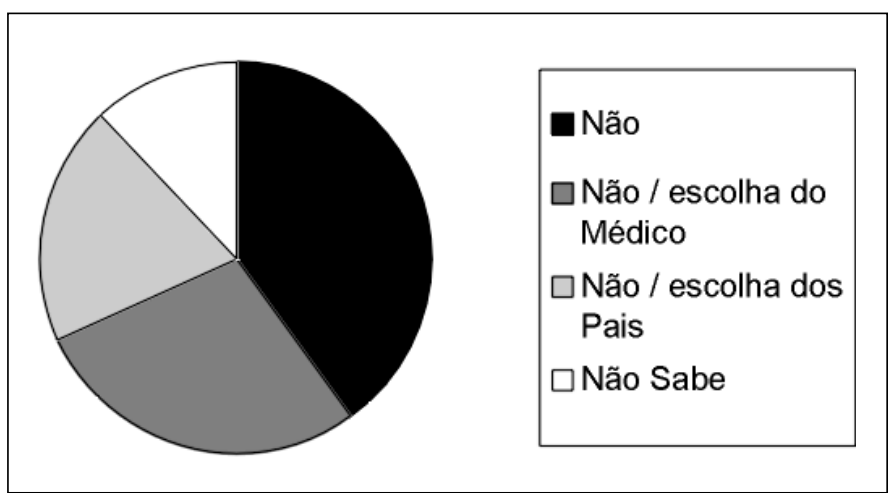

Gráfico 4 - Não participação na escolha de realizar consulta médica 


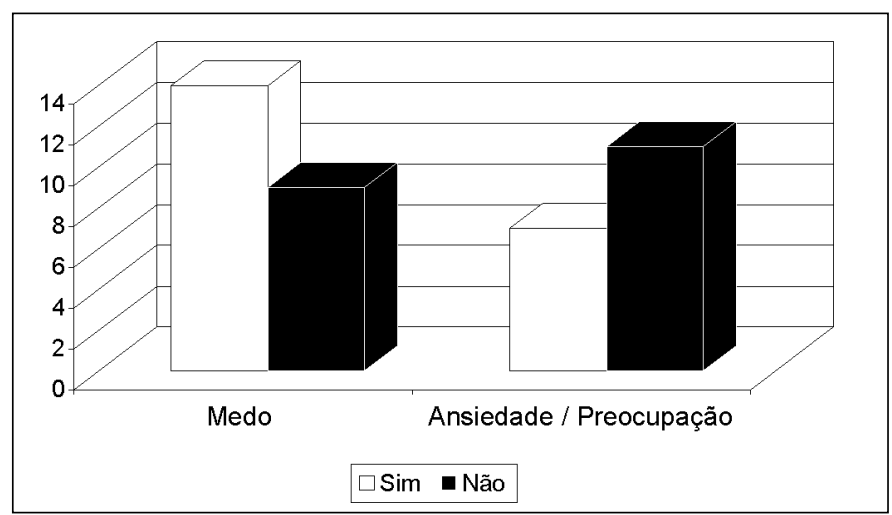

Gráfico 5 - Afirmação de medo e/ou preocupação devido à intervenção

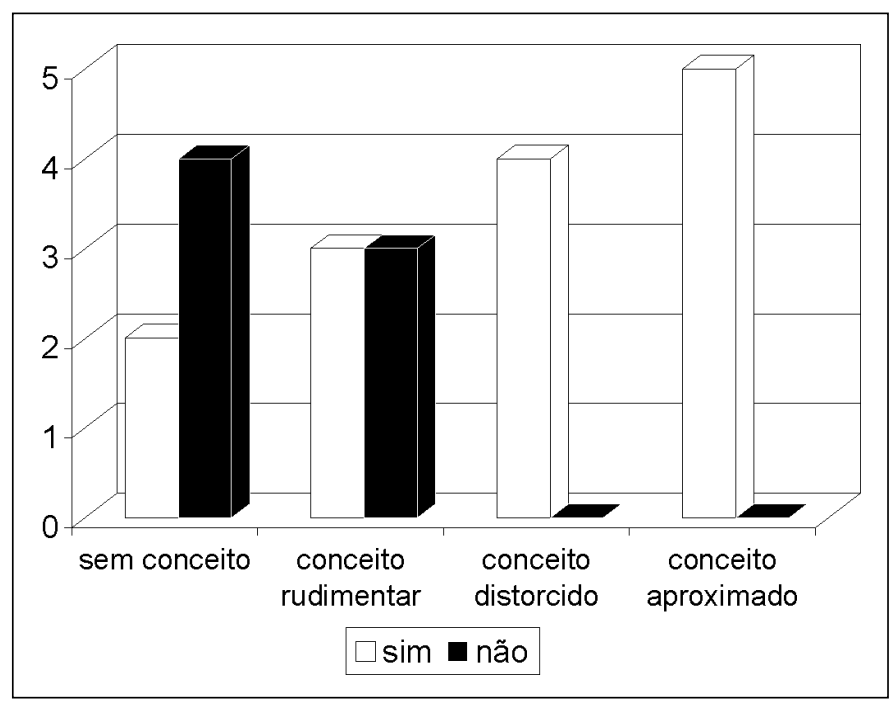

Gráfico 6 - "Correlação" entre tipo de conceito de cirurgia e medo frente à ela

As razões apresentadas pelos sujeitos para a presença à consulta, ou quanto à necessidade de intervenção, indicavam predominantemente a superação de situações estigmatizantes, especialmente provocadas por colegas de escola, mas também, por irmãos em seu ambiente familiar.

Poucos sujeitos da amostra, com mais de 5 anos, demonstraram não possuir qualquer conceito relativo à cirurgia: a maior parte dos sujeitos sem conceito aparente, teria 4 ou 5 anos de idade quando da entrevista.

Entre os sujeitos mais velhos que não haviam formado um conceito, dois freqüentavam instituições especiais, envolvendo inclusive déficit intelectual. Entretanto haviam crianças de 4 anos com um nível de informação suficiente para o evento.

Os sujeitos que apresentavam conceito "distorcido", o haviam adquirido de terceiros como tios, irmãos ou parceiros de brincadeiras. Apesar da experiência anterior, os poucos sujeitos da amostra que a tiveram, não formularam conceitos de fato adequados e tiveram a tendência a destacar sua vivência dolorosa, razão pela qual apresentavam medo de enfrentar outra experiência.
Alguns conceitos sobre cirurgia foram mais freqüentes tais como: arrumar, endireitar o olho ou colocar na posição, sendo que alguns sujeitos fizeram alusão à mexer no olho, com a inclusão da utilização de instrumentos, ou simplesmente mencionando a possibilidade de corte, indicando-o assim indiretamente; por outro lado algumas crianças descreveram esta situação como aquela em que a pessoa "toma um remédio, dorme, pode até sonhar, acorda e vai embora". Entre os conteúdos mais fantasiosos ou distorcidos, verificou-se o receio de ter os olhos "arrancados" ou retirados, ou de ficar cego, quer pela utilização da "instrumentação utilizada", quer por não tomar a providência cirúrgica. Neste caso, entretanto, foi marcante a participação de terceiros (irmãos, amigos ou colegas de escola, e até mesmo tios) na formação destes conteúdos.

A maior parte da amostra revelou sentir medo em relação à cirurgia, mas especialmente de sentir dor em virtude dela. Receio de mutilação e ansiedade de separação (principalmente entre crianças mais novas, entre 6 e 8 anos) também surgiram porém, respectivamente, de modo bem menos expressivo. Algumas crianças poderiam vir à apresentar ansiedade separação, uma vez que nunca haviam se distanciado de modo mais prolongado dos pais, e estes não as estavam informando sobre nada.

Algumas crianças demonstraram alívio em relação à ansiedade de separação por poderem compará-la ao afastamento temporário dos pais na situação escolar, cuja experiência já lhes era conhecida.

Como seria de se esperar, os que não tinham um conceito formado à época da entrevista não manifestaram, em sua maioria, medo em relação ao procedimento vindouro. Entre os que apresentavam conceito distorcido, com fantasia de mutilação todos apresentaram medo. Entre os que apresentaram conceito rudimentar pode-se dizer que amostra apresentou-se dividida, mas entre os sujeitos que tinham um conceito aproximado do procedimento, a presença do medo foi unânime (também presente entre os que tiveram intervenções anteriores).

\section{DISCUSSÃO}

Tecendo alguns comentários relativos aos dados em geral pode-se dizer que, quanto ao fato observado de que os sentimentos anteriores à consulta médica eram mais positivos que os posteriores a ela, esta constatação pode ser indicativa de satisfação do sujeito com o contato em si, com os resultados da consulta ou, simplesmente, efeito da eliminação de fatores ansiógenos imediatos. Pode-se afirmar que os sentimentos positivos prevaleceram sobre os de conotação negativa, indicando que de alguma forma o relacionamento com o profissional pode amenizar certas vivências.

Note-se, entretanto, que, apesar do discurso de bem estar, 10 das crianças entrevistadas apresentavam indícios claros de ansiedade conforme o item tratado (atitude física de apreensão, inquietude, relativa agitação motora) após consulta de indicação de cirurgia (4 de forma mais aguda e o restante de 
forma mais branda). Não foram observadas diferenças relativamente ao gênero sexual, se globalmente analisados os dados, porém diferenças quanto à faixa etária: predominante entre pacientes de 7 a 11 anos de idade do sexo feminino, e, entre pacientes do sexo masculino, de 11 a 14 anos.

Aparentemente vários sujeitos sentiam-se estigmatizados, ou mesmo discriminados, razão pela qual concordavam com a decisão dos pais de levá-los à consulta médica. Houve até quem afirmasse sentir-se rejeitado por apresentar estrabismo, o que permite deduzir que podem haver reflexos na formação da autoestima, bem como no desenvolvimento da socialização.

A precocidade da experiência anterior com intervenção cirúrgica, ou procedimento similar a ela, pode ser outro fator a ter dificultado a simbolização deste evento pela criança, destacando-se pois o registro do desconforto, e determinando a formação de um conceito de cirurgia um pouco mais precário. Note-se que o procedimento anterior não era relacionado à cirurgia ocular nesta amostra.

O fato é que há uma representação que a criança faz do vocábulo, quer para dar significação ao procedimento em si mesmo, construindo de fato um conceito, quer para representar os receios a ele associados, eminentemente subjetivo, aparentemente mais relacionados à forma da criança lidar com situações novas ou desconhecidas, manifestada por uma forma de conceituação mais rudimentar.

Apesar da afirmação de medo, as crianças mais velhas (entre 9 e 14 anos) conseguiam identificar relação custo/benefício concreta quanto ao resultado pretendido com a cirurgia: deixar de ser chamado de "zarolho", "olho torto", "quatro olho", "vesgo", ou seja, beneficio relativo à própria imagem e, "secundariamente", para as relações sociais; poucos apontaram para benefícios objetivos tais como: deixar de usar óculos, tampão, que para alguns sujeitos da amostra, representava impedimento para brincar com a mesma espontaneidade, impondo-lhes limitações cotidianas. Deste modo a motivação de ordem subjetiva mostrou-se dominante.

A aproximação da puberdade e adolescência pareceu ser motivação relevante para o mais velhos, fase na qual a imagem perante outrem assume especial conotação.

Note-se que, apesar do receio manifesto quanto à intervenção, várias crianças, especialmente as mais velhas, deixaram claro que, ainda assim, preferiam enfrentar o procedimento para atingir o objetivo pretendido: corrigir a posição do ocular e sentiam-se capazes de lidar com seu sentimento, supondose portanto que sua dimensão não era tão intensa, que não pudesse ser acolhida pela criança.

Não obstante, haver crianças de 4 anos com conceito melhor formado sobre o assunto, o que é mais raro, observouse que de um modo geral, crianças com até 9 anos tendem a relacionar a ocorrência de cirurgia ao desejo dos pais ou do médico, situando fora dela a motivação para que ocorra, sem dar-se conta de benefícios específicos que possa obter.

A postura dos adultos perante à cirurgia (que convivem com a criança), pareceu ter certo destaque neste grupo. Note-se que o desejo da criança mostrou-se relativamente mesclado com as decisões dos adultos. Nesta medida portanto é de se supor que a postura dos adultos venha a assumir importância como sinalizador da postura da criança frente ao evento.

Os sujeitos mais velhos embora também revelem medo, ansiedade ou preocupação, fazem-no de forma menos "fantástica" e parecem conseguir situar a motivação em si mesmos, relacionando-a a algum benefício pessoal, próprio, a ser obtido com o procedimento, o que sugere que a maturação emocional e cognitiva podem favorecer a elaboração do evento.

\section{CONCLUSÃO}

Ainda que a criança não tenha sido explicitamente informada sobre o que é e como ocorre uma cirurgia, quer pelos médicos, quer pelos pais, que possivelmente também tem pouca informação a respeito, ela estabelece um conceito mesmo que rudimentar com as informações que parece coletar do meio ambiente, em função do qual vivência medo / ansiedade, formulando, às vezes fantasias desproporcionais, também indicativas de pensamento pré-operatório ${ }^{(1)}$ do ponto de vista de desenvolvimento cognitivo ${ }^{(2)}$ mas simultaneamente, sinalizando uma vivência emocional especifica, eventualmente fóbica $^{(2)}$.

Assim, mais que a faixa etária isoladamente, o desenvolvimento cognitivo, especificamente o conceito que a criança consegue formular sobre o procedimento, com as informações que possui, e com o qual opera sobre a situação, parecem constituir, melhores indícios de sua possibilidade de lidar com o medo e / ou a ansiedade, que o evento vindouro lhe provoca.

Deste modo, mais que a informação detalhada ou minuciosa, a adequada informação ao seu nível de compreensão do sujeito, pode favorecer a postura da criança frente ao evento, embora não seja o único fator a ser levado em conta.

Evidentemente tanto o desenvolvimento emocional quanto cognitivo intervém na compreensão da criança sobre as situações que vivencia e, necessariamente, devem ser considerados na elaboração de qualquer intervenção preparatória das crianças para cirurgia, especialmente no âmbito psicológico.

O recorte simbólico que o sujeito faz nos dois níveis parece ser um dos cernes da questão.

ABS TRACT

Purpose: To identify the principal reactions of children facing strabismus surgery information as a result of its immediate and recent indication on medical consultation. Methods: Intervention/Action during Research; interview after surgery indication. Results: Anxiety and fear were the most important feelings encountered. They were sustained by partial concepts formed about surgery due the different levels of cogni- 
tive development of the children. The motivation for the surgery itself was only recognized among subjects older than 9 years. Children with less age had their surgery motivation mixed with the adults' purposes, especially parents, around them. Conclusions: The special meaning of this data seems to be that the symbolic function should be considered to psychologically prepare children for the surgery, in both directions: cognitive and emotional representation.

Keywords: Strabismus/surgery; Strabismus/psychology; Anxiety; Fear; Cognition; Parent-child relations; Child behavior disorders; Patient participation
REFERÊNCIAS

1. Shirley PJ, Thompson N, Kenward M, Johnston G. Parental anxiety before eletive surgery in children - a bristish perspective. Anaesthesia 1998; 53:956-9.

2. Salmon P. Surgery as a psychological stressor: paradoxical effects of preoperative emotional state on endocrine responses, stress. Medicine 1992;8:193-8.

3. Kain ZN, Wang SM, Caramico LA, Hofstadter M, Mayes LC. Parental desire for perioperative information and informed consent: a two-phase study. Anesth Analg 1997;84:299-306.

4. Sá LCF. Estrabismo nos anos 90. Arq Bras Oftalmol 1998;61:720-4.

5. Kain ZN, Mayes LC, O'Connor TZ, Ciccheti DV. Preoperative anxiety in children-predictors and outcomes. Archiv Pediatr Adolesc Med 1996;150: 1238-45.

\title{
I CONGRESSO DE OFTALMOLOGIA DAS UNIVERSIDADES DO RIO DE JANEIRO
}

\author{
15 a 17 de Novembro de 2001
}

\section{CAMPUS DA UNIVERSIDADE DO ESTADO DO RIO DE JANEIRO - UERJ}

\author{
APOIO: \\ Conselho Brasileiro de Oftalmologia e \\ Sociedade Brasileira de Oftalmologia \\ PATROCÍNIO: \\ Instituto de Oftalmologia de Niterói
}

Informações: LK Assessoria \& Promoções Ltda.

R. General Argolo, 113 - São Cristóvão

Cep: 20921-390 - Rio de Janeiro - RJ

Tels: (21) 3860-6906 / 3860-6363

Telefax: (21) 3860-6064

E-mail: evento@lk.com.br 